\title{
A Study of Saudi Advanced Academic Writing Students' Perceptions of Research Essays, and Gaps in Their Knowledge
}

\author{
Nida Qayoom and Mohammad Saleem \\ Department of English, King Abdulaziz University - Rabigh branch \\ Rabigh, KSA \\ https://orcid.org/0000-0003-1621-0646 \\ https://orcid.org/0000-0002-6709-2478
}

\begin{abstract}
The primary objective of the present research was to test the hypothesis that despite being trained in academic writing for one semester, there remain gaps in Saudi undergraduate English Major students' academic writing, especially pertaining to research essays. The secondary objective was to know how these students perceived academic writing. A mixed-methods empirical research using triangulation approach for results validation was conducted to identify gaps, if any, in students' knowledge in academic writing and to ascertain their perception of research essay writing, involving twenty undergraduate English Major students as research participants. Test and interview were used as data collection instruments, and the obtained data were analysed statistically. The results show that Saudi university English Major students regard academic writing tough, and acknowledge that for them it is the weakest area of competence in English. They have only a basic idea of how to find suitable sources for their research topics, to review relevant literature to contextualize their study, and to prepare notes and references for the study. The study is very significant since it highlights a major area of university students' weakness in studies and offers constructive suggestions.
\end{abstract}

Keywords: research writing; academic essays; students' perceptions on research essays; gaps in knowledge in writing

\section{Introduction}

Academic writing is an essential component of university students' training in writing in English since it's a decisive factor in their success in further studies as well as in jobs. It is a common observation that many university students in Saudi Arabia regard academic writing, especially research writing, a challenging task. Although English Major students are taught Academic Writing as a compulsory course for one semester, students lack practical knowledge to locate appropriate academic sources on/offline, build a convincing argument, find 
supporting research studies, and compile a list of references, etc. Thus, a strong need was felt to address the perceived gaps in students' knowledge.

\subsection{Research Background}

One of the ways to teach adult students writing focused essays is to introduce them to the style of research article/writing for publication (Amerian \& Marefat, 2019; Bailey, 2011; Crème \& Lea, 2000; Goalty, 2000; Hogue \& Oshima, 2006; Joseph, 1998). With this caveat in view, to teach academic essay writing to $3^{\text {rd }}$ year English Major (Academic Writing) students, the researchers incorporated in their teaching the elements of advanced research writing, especially the methods of compiling short literature reviews to situate the essay in the given academic context, locating the sources for materials, summarizing the published research findings, and building one's arguments (Ahmed, 2016; Al-Badi, 2015; Al-Khairy, 2013). Moreover, the students in the course are supposed to learn how to incorporate the essential elements of research in their academic essay writing as they need to conduct a mini-research project on a selected topic (The observation is based on the course description for Academic Writing' course at the King Abdulaziz University - Rabigh branch [KSA]). Although it is not exactly oriented towards writing a research paper for publication, yet the work on the project is a great way to learn writing essays modelled on a research paper in focus, on a concise specialized topic, finding materials on/offline, preparing a review of literature for contextualization of the essay, formatting, organizing, argument building, documenting in-text citations, compiling notes, learning different referencing styles, and preparing the list of works cited.

\subsection{Research Problem}

As a pre-requisite to Academic Writing, students in English Major stream do take a course in research methodology for a semester in which they learn incorporating the fundamental elements of 'writing for research' in their academic essays. But it has been noticed that the majority of them are found lacking in translating their theoretical knowledge into practice (Alkutbi, 2018; Ankawi, 2015; Shukri, 2014). Their greatest challenges in writing researchoriented academic essays are observed to be in reviewing the existing literature (what the sources relevant to their research essays are and how to write a review of previous research), citing academic sources and compiling the list of works cited (Alharbi, 2019; Fadel \& Rajab, 2017). In Saudi Arabian contexts there is very little research in this area of academic inquiry, though researchers working in second language writing issues have identified several aspects of writing weaknesses and the ways to improve students' writing (Al Badi, 2015; Alharbi, 2019; Ansari, 2012). There is still less research work on the experimental use of teaching writing for research essays to encourage the students to grasp the fundamental principles of academic writing. The issues in academic writing persist with Saudi students and cause other performance-related drawbacks after they enrol at western universities in English-speaking countries (Alhojailan, 2015). In the opinion of Alhojailan (2015), the problem is related to Saudi students' poor understanding of the purpose of academic writing, "the participants might have a limited understanding of the meanings and of the purpose of academic writing" (p. v). Often students are not encouraged to write long answers to test questions; they vomit the little they swallow for the exams, 
nothing more. As a result, students in Saudi Arabia commonly perceive writing as the most difficult task, and it is still harder to bring them round to write for research (Al-Mudhi, 2019; Alkutbi, 2018; Ahmed, 2016; Al-Badi, 2015; Al-Khairy, 2013; Huwari \& Al-Khasawneh, 2013). The gaps in their knowledge in academic/research writing need to be bridged to prepare them for further studies, in English as well as in other subjects.

\subsection{Research Hypotheses}

Based on the background information, the research problem identified in the process and the preliminary review of existing literature, the researchers have designed the present research to test the following hypotheses:

RH 1: Saudi Academic Writing (English Major) course students perceive academic essay writing an extremely difficult task.

RH 2: There are gaps in Saudi Academic Writing students' knowledge in research essay writing.

\subsection{Research Questions}

The hypotheses stated above are to be tested in the study by seeking answers to the following research questions:

$R Q$ 1: How do Saudi Academic Writing (English Major) students perceive academic essay writing?

$R Q$ 2: Are there gaps in Saudi Academic Writing students' knowledge in research essay writing?

\subsection{Research Objectives}

The primary objective of the intended research was to identify gaps, if any, in Saudi Academic Writing students' knowledge in academic (research essay) writing. The secondary objective of this research was to gather documentary evidence on Saudi adult students' perceptions regarding academic writing, which includes recording their views on writing a review of existing literature, using in-text citations, and compiling notes and bibliography. Both these objectives were aligned to students' present academic needs since the students are required to work on a mini-research project prescribed in their study programme.

\section{Literature Review}

Academic writing is a very significant area of research in English language teaching, and therefore, a good body of research literature exists in this field. The studies most relevant to the present topic of research, and studies conducted in Saudi Arabian context, have been reviewed for contextualization and justification of the present research.

\subsection{Academic Writing}

Academic writing, as defined in the Research Guide section at the University of South Carolina website, "refers to a style of expression that researchers use to define the intellectual boundaries of their disciplines and their specific areas of expertise" (USC Libraries, Research Guides, 2020, para 1). ${ }^{i}$ Accordingly, 
academic writing is characterized by a formal tone, use of the third-person perspective, a clear focus on the research problem under investigation, and precise word choice. Hartley's (2008) opinion on the nature of academic writing squares well with the guidelines provided here, especially concerning directness, simplicity, and clarity in academic writing (p. 8).

The Academic Writing course at the King Abdulaziz University, Rabigh branch where this research has been conducted, also has been designed keeping in view the essential features of academic writing requirements of learners. The course focuses on the content, structure, and organization of academic essays. The learners are expected to work to correctly incorporate research into their essays. Advanced sentence structures, summarizing, paraphrasing, correct use of citations, proofreading skills, and critical reading are addressed in the course. The main aim of the course is to polish students' skills in academic writing conventions and equip them with a firm understanding of the process of writing a research paper at the graduate level. The main orientation of the course is that students- (i) understand that academic writing is a process and a skill which needs to be acquired through practice, (ii) recognise that reading and thinking skills are two key factors in improving writing, (iii) develop writing skills and strategies that are necessary for a research paper at the graduate level, (iv) identify the writing process of planning a research paper; from writing the outline to proofreading the final draft, and (v) be familiar with the most common research process problems that graduate students face.

Thus, comprehending the fundamental principles of academic writing is essential for undergraduate students for excellent performance in (i) further studies, if they continue university studies for masters' degree courses or research studies, (ii) studies abroad, and (iii) jobs where academic style writing skills are required, such as journalism, editing, teaching, etc.

Excellent academic writing skills are the fundamental key to success not only in writing-related jobs but also for studies in various disciplines not directly related to writing. The basic tenets of English for Academic Purposes (EAP) are formulated keeping in mind the development of academic writing skills of students in various disciplines as Paltridge and Starfield (2013) observe that, "EAP courses in various disciplines are designed as a conduit between academic research and practical applications" (p. 175). For example, Surratt (2006), highlighting the need for an academic writing course for students in the pharmaceutical profession, says:

There are 3 compelling reasons for a pharmacy school to insist that its graduate students acquire excellent oral and written communication skills before receiving the MS or PhD degree: to ensure that doctor of pharmacy (PharmD) student training by these teaching assistants is of the highest quality, to fully prepare the graduate student for employment, and to enrich the pool of future pharmacy faculty candidates. (Surratt, 2006, p. 2) 
Studies on the problems faced by international students at universities in English-speaking countries show that numerous students enrolled in various study programmes fail to perform well only because they do not have sufficient preparation in academic writing skills, along with other drawbacks in comprehending academic English (Al-Mudhi, 2019; Alzaharani, 2016; Chittum \& Bryant, 2014). Evans and Morrison (2011), in their study conducted with international students, observe that "The evidence suggests that the students' principal sources of difficulty were comprehending and using specialist vocabulary, understanding their professors' academic requirements and processing and producing key disciplinary genres" (p. 387). The case might be even a little worse with Saudi students since Saudi students admit that they consider writing as the most challenging area of language learning, as report Grabe and Kaplan (2014). The researchers show that their quantitative (skill ratings) and qualitative (responses to open-ended questions and interviews) data suggest that both students and instructors view writing as a challenging area for Saudi English-language learners. Though the situation may be found to be similar in other contexts as well. For instance, from Turkey, Altinmakas and Bayyurt (2019) in their research findings report that undergraduate writing is influenced by an array of interrelating educational and contextual factors, such as the amount of L1 and L2 pre-university writing instruction and experience, students' perceptions of academic writing and disciplinary-specific text genres, prolonged engagement with the academic context and discourse, and expectations of faculty members.

Research studies show that undergraduate learners need support in developing academic writing, but in most cases, this support is found missing in undergraduate programmes (Bacon \& Anderson, 2004; Chittum \& Bryant, 2014; Fischer \& Zigmond, 1998). As a result, writing can become a painful exercise and a task causing much anxiety in many graduate students (Pfeifer \& Ferree, 2006; Singleton-Jackson, Lumsden \& Newsom, 2009). Rose and McClafferty (2001), for instance, enumerate several issues learners usually have in a graduate course in professional writing, such as problems in style, grammar, logic, and voice, that lead to writing anxiety.

\subsection{Research on Academic Writing in Saudi Arabia}

In the Saudi Arabian context, there is very little research in this area of academic inquiry, though researchers working in second language writing issues have identified several aspects of writing weaknesses and the ways to improve students' writing in general (Ahmed, 2016; Al Badi, 2015; Alharbi, 2019; AlKhairy, 2013; Alkubaidi, 2014; Ansari, 2012; Huwari \& Al-Khasawneh, 2013; Khan, 2011). The focus of ESP/EAP practitioners, too, in Saudi Arabia is on the socialization of specific course students, like doctors, engineers, lawyers, etc. into their respective academic fields using English language (Ezza \& Al-Jaralla 2015) rather than on developing specific skills, such as reading or writing. There exist no research works on employing writing-for-research and publication to enhance learners' academic writing skills. 
Therefore, the present study is encouraged by ideas from other settings. For instance, Doyle (2008) notes that utilizing a practice-based approach that enables graduate students to participate in the publication process is ideal for the development of their academic writing. Kamler (2008) believes that greater attention to writing for publication in higher education is needed since the process provides a sharp edge to students' academic writing. Although Kamler (2008) is primarily speaking from the vantage point of research scholars working towards their $\mathrm{PhD}$ dissertations, his views are equally valid for graduate students' academic writing.

\section{Research Methodology}

The present study uses triangulation method to validate the obtained results. The data have been collected through two sources - (i) an assignment given to the students to solve, and (ii) an interview structured on the points similar to assignment questions. The study employs mixed methods, i.e., quantitative and qualitative analysis methods. The assignment and interviews supplied numerical data as both were marked using a marking scheme. Both the assignment and the interview were structured around ten research variables, framed into ten different questions. Each question was assigned four marks, making a total of forty marks each for the assignment as well as the interview format. The numerical data obtained thus were interpreted qualitatively to present a narrative analysis of results. The last question in the interview format was meant to gather students' perceptions of academic writing (research essay), thus, it was also meant to collect qualitative data.

\subsection{Data Collection}

The data for the study were collected through two different instruments (Appendix A and B), viz., assignment and interview. In the sub-sections that follow is provided the detailed description of the instruments, the research participants and the data collection procedure.

\subsubsection{Assignment}

The assignment given to participants to prepare a focused academic essay on a given topic was used as a quantitative data collection instrument. The assignment was based on an academic observation and the participants were asked to prepare the outline of a research essay under the following sections: research problem, hypothesis and research questions, research aims, relevant existing literature, significance of the research, summary of three previous research articles relevant to the study, research argument, citation of the sources, and list of references. Each research variable was assigned 4 marks, making a total of 40 marks. The variables were set in accordance with the standard organizational structure of research articles, that is, IMRAD (Introduction, Method, Results, and Discussion (Hartley, 2008)). The validity and reliability of the sections were determined by calculating Chronbach's Alpha for the test, which measured .716, a quite satisfactory value (the minimum acceptable value being .61). The objective of the assignment was to identify gaps in the knowledge of participants on the idea and format of a research essay. 


\subsubsection{Interview}

For the purpose of triangulation, data were collected on the same topic through yet another instrument, i.e., structured interviews. Data were collected from the same set of participants on the same set of research variables, except that the last question in the interview format was meant to gather qualitative data on participants' perceptions of academic writing. Again, each variable was assigned 4 marks, making a total of 40 marks for the interview. In this case too, the validity and reliability of interview questions were determined through Chronbach's Alpha, the obtained value of which was .877, a good value to start with. Kvale and Brinkmann's (2009) suggestions on conducting semistructured/structured interviews were also followed to a large extent in preparing the interview format. The participants were interviewed on their perception of research essays and academic writing in general, and their understanding of what research in English language or literature is. The objective of the interview was to evaluate students' awareness of research writing as part of learning academic English.

\subsubsection{Participants}

Twenty students were selected to take part in the study. In fact, the total number of students in the Academic Writing class was 20, so, all were encouraged to take part in the research study. They are $3^{\text {rd }}$ year ( $5^{\text {th }}$ semester) students in a 4year (8 semesters) undergraduate course majoring in English. The participants have already studied several core modules offered in English Major study course. These students are supposed to write a mini-research project in the final year of their study, which requires training in research methodology. All the participating students were female, aged between 21-24 years.

\subsubsection{Procedure}

The assignments were printed with clear instructions and enough space to write answers to questions. Students were asked to complete the assignment in the class, just like a class-test, to avoid any malpractices. Full marks (4) were given for each complete and correct response, and in accordance with errors and incomplete responses, marks were deducted. Thus, students' obtained marks ranged from 0 to 4 . Similarly, the interviews conducted orally were marked on a printed format. The interview format, being structured, contained similar questions for all the participants to avoid bias in data collection. Since the interview questions also tested students' knowledge of research writing, 4 marks were allotted to each full and correct answer, and marks were deducted for errors and incompleteness.

\section{Discussion and Analysis}

The quantitative results obtained from the assignment and interviews were analyzed statistically to calculate Chronbach's Alpha, Means of scores, Standard Deviation, and Variance. The values obtained from the analysis were used to make a qualitative association for narrative interpretation. Students' responses to the last question in the interview format were analyzed to judge students' perceptions of academic writing. Marks obtained by participants in assignment and interviews were analyzed to identify the gaps in the knowledge of 
participants (marked by any discrepancy between the knowledge the participants actually have and the current requirements of Academic Writing, i.e., the knowledge the participants are supposed to have at this stage).

\subsection{Results}

For the assignment, the participants were given the task to -

1. identify the research problem correctly,

2. form research hypothesis and research questions,

3. choose an appropriate research methodology,

4. set the aims and objectives of the research,

5. find appropriate sources to contextualize the research,

6. write appropriate significance of the research,

7. summarize the relevant materials (at least three articles),

8. build research argument,

9. cite the sources (in-text citation) in the style of participants' choice, and

10. prepare a reference list in the chosen style.

Scores obtained by each participant are given in Table 1 below:

Table 1: Mean, standard deviation, variance, and Cronbach's Alpha for the test assignment

\begin{tabular}{|c|c|c|c|c|c|c|c|c|c|c|c|}
\hline & R Prob & Hypo. \& Q. & R. Meth. & Aims & Source & Signifi. & Summary & Argument & Citation & Refer. & Total \\
\hline 1 & 2 & 1 & 4 & 2 & 2 & 4 & 1 & 2 & 4 & 1 & 23 \\
\hline 2 & 2 & 4 & 4 & 4 & 2 & 2 & 2 & 4 & 4 & 4 & 32 \\
\hline 3 & 4 & 4 & 4 & 2 & 4 & 4 & 4 & 1 & 2 & 2 & 31 \\
\hline 4 & 1 & 2 & 1 & 1 & 2 & 4 & 2 & 2 & 1 & 2 & 18 \\
\hline 5 & 4 & 2 & 4 & 2 & 1 & 2 & 4 & 4 & 3 & 4 & 30 \\
\hline 6 & 4 & 4 & 4 & 4 & 4 & 4 & 4 & 2 & 2 & 2 & 34 \\
\hline 7 & 2 & 4 & 2 & 3 & 2 & 4 & 4 & 4 & 4 & 4 & 33 \\
\hline 8 & 2 & 2 & 2 & 2 & 4 & 2 & 1 & 4 & 2 & 1 & 22 \\
\hline 9 & 3 & 1 & 3 & 1 & 3 & 4 & 0 & 1 & 2 & 2 & 20 \\
\hline 10 & 2 & 4 & 1 & 4 & 1 & 3 & 1 & 4 & 4 & 2 & 26 \\
\hline 11 & 2 & 4 & 4 & 4 & 2 & 1 & 1 & 2 & 1 & 1 & 22 \\
\hline 12 & 4 & 2 & 4 & 4 & 4 & 4 & 4 & 4 & 4 & 4 & 38 \\
\hline 13 & 3 & 3 & 3 & 4 & 2 & 3 & 1 & 4 & 2 & 2 & 27 \\
\hline 14 & 4 & 2 & 2 & 1 & 4 & 2 & 2 & 2 & 4 & 4 & 27 \\
\hline 15 & 2 & 4 & 4 & 4 & 2 & 4 & 4 & 4 & 4 & 2 & 36 \\
\hline 16 & 2 & 2 & 3 & 2 & 2 & 1 & 2 & 1 & 1 & 1 & 17 \\
\hline 17 & 4 & 2 & 4 & 4 & 2 & 4 & 4 & 2 & 4 & 2 & 32 \\
\hline 18 & 1 & 3 & 4 & 4 & 1 & 4 & 4 & 4 & 4 & 4 & 33 \\
\hline 19 & 4 & 2 & 2 & 1 & 2 & 3 & 2 & 1 & 1 & 2 & 20 \\
\hline 20 & 3 & 2 & 4 & 2 & 2 & 4 & 2 & 2 & 4 & 4 & 29 \\
\hline \multicolumn{12}{|l|}{ Total } \\
\hline Mean & 2.75 & 2.7 & 3.15 & 2.75 & 2.4 & 3.15 & 2.45 & 2.7 & 2.85 & 2.5 & 27.5 \\
\hline SD & 1.069 & 1.080 & 1.089 & 1.25 & 1.046 & 1.089 & 1.394 & 1.260 & 1.268 & 1.192 & 6.25 \\
\hline Var. & 1.0875 & 1.11 & 1.127 & 1.48 & 1.04 & 1.12 & 1.847 & 1.51 & 1.527 & 1.35 & 37.15 \\
\hline K & 10 & & & & & & & & & & \\
\hline$\Sigma$ var & 13.205 & & & & & & & & & & \\
\hline Var. & 37.15 & & & & & & & & & & \\
\hline a & 0.716 & & & & & & & & & & \\
\hline
\end{tabular}

Where -

$$
\begin{aligned}
& \mathrm{SD}=\text { Standard Deviation } \\
& \text { Var. = Variance } \\
& \mathrm{K}=\text { Number of variables } \\
& \Sigma \mathrm{Var}=\text { Sum of Variance }
\end{aligned}
$$


Thus, Cronbach's Alpha (a) is:

$$
\begin{aligned}
& \alpha=(k /(k-1)) \times(1-\Sigma \text { Var/Var }) \\
& \alpha=(10 /(10-1)) \times(1-13.205 / 37.15) \\
& \alpha=.716
\end{aligned}
$$

The results may be graphically presented as in Figure 1 below:

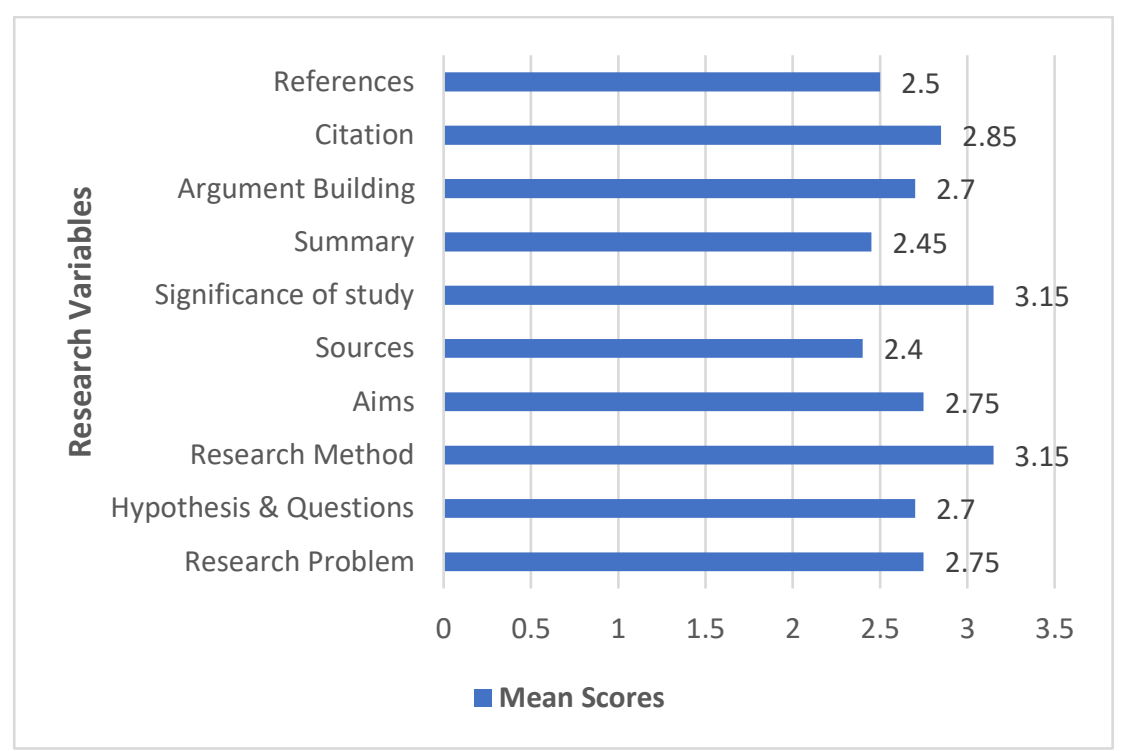

Figure 1: Means of scores obtained by students in each variable in the test assignment

The scores obtained by participants in the interview are given in Table 2 below:

\begin{tabular}{|c|c|c|c|c|c|c|c|c|c|c|c|}
\hline & R. Compo & R. Meth. & Context. & Hypo. \& Q. & Sources & $\begin{array}{c}\text { Citation of } \\
\text { sources }\end{array}$ & $\begin{array}{c}\text { In-text } \\
\text { citation }\end{array}$ & Format. & Refere. & Notes & Total \\
\hline 1 & 3 & 3 & 1 & 2 & 1 & 3 & 2 & 4 & 2 & 4 & 25 \\
\hline 2 & 3 & 3 & 2 & 4 & 1 & 4 & 3 & 4 & 2 & 4 & 30 \\
\hline 3 & 4 & 3 & 1 & 3 & 1 & 4 & 4 & 4 & 2 & 4 & 30 \\
\hline 4 & 2 & 3 & 2 & 3 & 2 & 4 & 3 & 2 & 2 & 2 & 25 \\
\hline 5 & 4 & 3 & 1 & 4 & 2 & 3 & 4 & 3 & 1 & 3 & 28 \\
\hline 6 & 4 & 4 & 2 & 3 & 2 & 4 & 4 & 4 & 2 & 3 & 32 \\
\hline 7 & 4 & 4 & 2 & 4 & 2 & 3 & 4 & 4 & 2 & 3 & 32 \\
\hline 8 & 3 & 3 & 2 & 2 & 2 & 2 & 2 & 3 & 2 & 4 & 25 \\
\hline 9 & 1 & 2 & 0 & 2 & 2 & 3 & 1 & 2 & 1 & 1 & 15 \\
\hline 10 & 3 & 3 & 2 & 3 & 2 & 4 & 4 & 3 & 2 & 4 & 30 \\
\hline 11 & 3 & 3 & 2 & 3 & 1 & 3 & 2 & 3 & 2 & 4 & 26 \\
\hline 12 & 4 & 4 & 3 & 4 & 2 & 4 & 4 & 4 & 3 & 4 & 36 \\
\hline 13 & 3 & 3 & 2 & 3 & 0 & 3 & 2 & 2 & 2 & 2 & 22 \\
\hline 14 & 3 & 4 & 2 & 3 & 1 & 4 & 4 & 2 & 1 & 3 & 27 \\
\hline 15 & 3 & 3 & 2 & 4 & 1 & 4 & 4 & 4 & 2 & 3 & 30 \\
\hline 16 & 2 & 2 & 0 & 2 & 0 & 2 & 2 & 3 & 2 & 2 & 17 \\
\hline 17 & 3 & 4 & 1 & 4 & 2 & 4 & 3 & 4 & 2 & 3 & 32 \\
\hline 18 & 2 & 4 & 2 & 4 & 2 & 4 & 4 & 4 & 3 & 4 & 33 \\
\hline 19 & 3 & 3 & 2 & 3 & 2 & 4 & 3 & 4 & 3 & 4 & 31 \\
\hline 20 & 3 & 3 & 1 & 2 & 2 & 3 & 2 & 3 & 2 & 2 & 23 \\
\hline \multicolumn{12}{|l|}{ Total } \\
\hline Mean & 3.0 & 3.2 & 1.6 & 3.1 & 1.5 & 3.45 & 3.05 & 3.3 & 2.0 & 3.15 & 27.45 \\
\hline SD & .794 & .615 & .753 & .788 & .688 & .686 & .998 & .801 & .561 & .933 & \\
\hline Var. & .60 & .36 & .54 & .59 & .45 & .4475 & .9475 & .61 & .30 & .827 & \\
\hline K & 10 & & & & & & & & & & \\
\hline$\Sigma$ var & 5.667 & & & & & & & & & & \\
\hline Var. & 26.947 & & & & & & & & & & \\
\hline 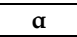 & .877 & & & & & & & & & & \\
\hline
\end{tabular}

Table 2: Mean, standard deviation, variance, and Cronbach's Alpha for interview responses 
The results may be graphically represented as in Figure 2 below:

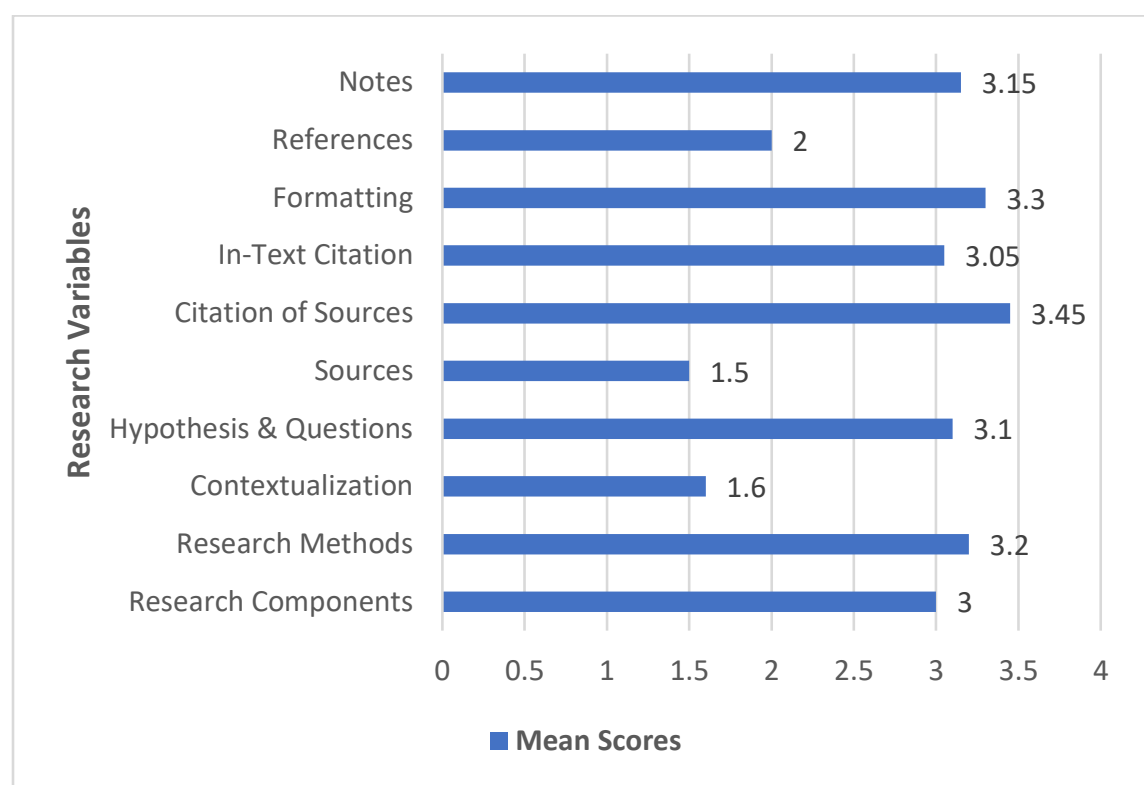

Figure 2: Means of scores obtained by students in each variable in the interview questions

\subsection{Research Findings}

A glance at Table 1 shows that the mean scores of participants are the highest in describing the research methodology (3.15) and describing the significance of the study, followed by the citation of sources (2.85) and describing the aims and objectives of the study (2.75), whereas, the lowest means of scores are observed in: locating the sources (2.4), writing a summary of previous research (2.45), preparing the reference list (2.5), and building the argument for the study (2.7). The results obtained from the assignment are corroborated by the results obtained from the interview responses. A look at Table 2 reveals that the highest means of scores are observed in the citation of sources (3.45), followed by formatting of the article (3.3) and describing research methods (3.2), whereas, the lowest means of scores are recorded in locating sources for materials collection (1.5), contextualization of the study (1.6), and preparing reference list (2.0).

The obtained results indicate that Saudi students in Academic Writing (English Major) programme find it hard to locate sources to collect materials relevant to their writing on/offline. The second source of their difficulty is to prepare a summary of relevant research articles to contextualize their writing even if they succeed in locating them. They are equally at a loss to prepare a reference list in proper format and build a strong argument for their research writing. The obtained results provide sufficient support to answer research question 2, "Are there gaps in Saudi Academic Writing students' knowledge in research essay writing?" The answer to the question is in the affirmative. Saudi Academic Writing students lack proper training in locating on/offline sources relevant to their mini-research writings, preparing a summary of relevant articles to contextualize their writing, preparing a well-formatted reference list, and building a convincing thesis argument. Therefore, the research hypothesis 2, i.e., 
'There are gaps in Saudi Academic Writing students' knowledge in research essay writing' is proven by numerical evidence gained from data analysis. The research finding also corroborates findings from previous research studies in Saudi Arabian contexts, such as Alzaharani (2016), Chittum and Bryant (2014), and Al-Mudhi (2019). But, such a state of affairs may not be confined to only Saudi Arabian students as Evans and Morrison (2011), in their study with international students' writing difficulties, report that the students' principal sources of difficulty were comprehending and using specialist vocabulary, understanding their professors' academic requirements and processing and producing key disciplinary genres, though Grabe and Kaplan (2014) pinpoint Saudi students facing specific issues with writing.

To answer research question 1, we need to turn to participants' responses to the last question in the structured interview format, i.e. "How do you feel about writing a research essay? Do you find the task easy or difficult?" The participants' responses indicate that the majority of them perceive writing a difficult task and writing a research essay is still more difficult for them. The major, common difficulties enlisted by most students pertain to materials collection, contextualization of the essay, summarizing the findings of previous researchers, and compiling a bibliography. For example, participant 1 says that:

To me, writing is the most difficult task. It is difficult because it requires using a particular type of vocabulary, sentence structure, and build an argument for what you are writing.

Participant 2 says:

Writing in English is the hardest part of learning the English language. Grammar, spelling, punctuation and sentence structure, all prove to be very difficult to me.

In the opinion of Participant 3,

Writing is difficult for me because first I have to collect ideas, then supporting ideas, then format the writing in a particular style. All this is so challenging.

Participant 4 has similar observations on writing:

Academic research essay writing is not an easy job for me. I have little idea how to find relevant source material. Then I have to put my writing in a research context and use some format for within the text citation of source materials. I find it very difficult.

Participant 5 echoes the opinion of participant 4 when he says, Writing a research essay is not simple. Apart from good grammar and suitable vocabulary, I have to learn different in-text citation styles and the methods of compiling notes and bibliography. But more than that, it is not easy to find materials that are suitable for my purpose.

Participant 6 opines that

students need more time to learn academic writing because it is special kind of writing, not like writing a simple essay. Choosing the right tone in research essay poses a challenge to me, and I find difficult to prepare a good references list because I am not sure which authors to take and which to reject for my study. 
To sum up, the answer to research question 1, "How do Saudi Academic Writing (English Major) students perceive academic essay writing?" is that to Saudi Academic Writing students, research writing poses tough challenges, and to most of them it is their weakest area of competence in English. Thus, it can be stated that research hypothesis 1, i.e., 'Saudi Academic Writing (English Major) course students perceive academic essay writing an extremely difficult task' is supported by research.

As has been noted in the literature review, in Saudi Arabian contexts there is very little research on students' difficulties in academic writing, but still, the findings from the present study are found to agree with the findings of those researchers who have worked on second language writing issues, such as AlBadi (2015), Alharbi (2019), Al-Khairy (2013), Alkubaidi (2014), Ansari (2012), Ezza and Al-Jaralla (2015), Huwari and Al-Khasawneh (2013), and Khan (2011).

\section{Conclusion}

To conclude, the present research study was taken up to identify potential gaps in Saudi Arabian English Major undergraduate students' knowledge in academic writing, and to gather documentary evidence on Saudi adult students' perceptions regarding academic writing. Analysis of the obtained results reveal that there do exist certain gaps in students' mastery in academic writing, especially in research essay writing. In addition, the students are found to regard academic writing their weakest spot in English language competence. In conclusion, both the research hypotheses have been accepted and the research questions have been answered. Although, since the current topic of research has been least explored in Saudi Arabian contexts, the findings of the present research could not be situated in a comparative perspective, yet it is hoped that they will prove to be of much help to forthcoming researchers. Taking the findings of the present research into cognizance, teachers of academic writing at Saudi universities may take some steps at their own level to help learners overcome the perceived difficulties.

\section{Limitations of the Study and Suggestions for Improvement}

The study is very significant in its settings, for two reasons: (i) The research findings suggest that academic writing is perceived to be a difficult task by Saudi Arabian university students. Academic writing is an extremely important component and a decisive factor in students' success in further studies, at home or abroad, as well as in jobs. To encourage students to write more, the examination pattern emphasizing long answer questions needs to be adopted in subject-specific situations. (ii) The findings reveal that there are gaps in Saudi English Major students' knowledge in academic writing, especially pertaining to locating academic sources on/offline, summarizing previous research studies, and compiling the reference list. All these are not only their current requirements but future requirements as well. The suggestion is that students should be given more assignments to write mock research papers for publication, with incentives such as including the name of the student whose paper is adjudged the best with the name of the faculty as co-author, if the paper is contributed to a research journal. 
Two limitations have been noted during the course of the present study which might have affected the obtained results: (i) Owing to limited resources and constraints of time, the present study has been conducted with a smaller set of participants. Further researchers may conduct similar studies with a larger number of participants and check whether they obtain similar results, and (ii) Due to segregated campuses for male and female students, the researchers could not include male students as participants in the study, which might have affected the results on students' perceptions. Further research works may record male students' opinions as well and see if the perceptions differ.

\section{References}

Ahmed, F. E. Y. (2016). An investigation of writing errors of Saudi EFL university students: A case study of college of science and arts - Tanumah, King Khalid University. International Journal of Social Science and Humanities Research, 4(2), 189211. http://dx.doi.org/10.13140/RG.2.2.22379.18725

Al Badi, I. A. H. (2015). Academic writing difficulties of ESL learners. The 2015 WEI International Academic Conference Proceedings, 65-78. Retrieved from https://www.westeastinstitute.com/wp-content/uploads/2015/02/IbtisamAli-Hassan-Al-Badi-full-Paper.pdf

Alharbi, M. A. (2019). EFL university students' voice on challenges and solution in learning academic writing. Indonesian Journal of Applied Linguistics, 8(3), 577-588. https://doi.org/10.17509/ijal.v8i3.15276

Alhojailan, A. (2015). Perceptions of academic writing by some Saudi graduate students studying in American universities (Doctoral dissertation, Oklahoma State University, Stillwater, OK, United States). Retrieved from https:// pdfs.semanticscholar.org/f5f8/8ec982c26d5a63d1a55cf04845b9ee4f9d53. pdf

Al-Khairy, M. A. (2013). Saudi English major undergraduates' academic writing problems: A Taif University perspective. English Language Teaching, 6(6), 1-12. http://dx.doi.org/10.5539/elt.v6n6p1

Alkubaidi, M. A. (2014). The relationship between Saudi English major university students' writing performance and their learning style and strategy use. English Language Teaching, 7(4), 83-95. http:/ / dx.doi.org/10.5539/elt.v7n4p83

Alkutbi, D. (2018). Bridging the gap: A study of academic language learning needs of Saudi international students (Doctoral dissertation, University of Victoria, Victoria, Canada). Retrieved from https://dspace.library.uvic.ca/bitstream/handle/1828/10126/Alkutbi_Douaa_ PhD_2018.pdf?sequence $=1 \&$ isAllowed $=y$

Al-Mudhi, M. A. (2019). Evaluating Saudi university students' English writing skills using an analytic rating scale. Journal of Applied Linguistics and Language Research, 6(4), 95-109. Retrieved from http://www.jallr.com/index.php/JALLR/article/view/1034/pdf1034

Altinmakas, D., \& Bayyurt, Y. (2019). An exploratory study on factors influencing undergraduate students' academic writing practices in Turkey. Journal of English for Academic Purposes, 37, 88-103. https://doi.org/10.1016/j.jeap.2018.11.006

Alzaharani, N. A. (2016). Saudi students' experiences of learning English in English as a foreign and second language settings (Master's thesis, Mount Saint Vincent University, Halifax, Nova Scotia, Canada). Retrieved from http:/ / dc.msvu.ca:8080/xmlui/bitstream/handle/10587/1768/NagahAlzahara niMAEDThesis2016.pdf?sequence $=1 \&$ isAllowed $=y$ 
Amerian, M., \& Marefat, F. (2019). A triangulated study of professional English needs of university graduates in business and economics in today's Iranian business sectors. Applied Research on English Language, 8(2), 227-260. https://doi.org/10.22108/are.2019.114847.1401

Ankawi, A. (2015). The academic writing challenges faced by Saudi students studying in New Zealand (Master's thesis, Auckland University of Technology, Auckland, New Zealand). Retrieved from https:/ / openrepository.aut.ac.nz/bitstream/handle/10292/9187/AnkawiA.pdf ?sequence $=3 \&$ is Allowed $=y$

Ansari, A. A. (2012). Teaching of English to Arab students: Problems and remedies. Educational Research, 3(6), 519-524. Retrieved from https://www.interesjournals.org/articles/teaching-of-english-to-arab-studentsproblems-and-remedies.pdf

Bacon, D. R., \& Anderson, E. S. (2004). Assessing and enhancing the basic writing skills of marketing students. Business Communication Quarterly, 67(4), 443-454. https://doi.org/10.1177/1080569904271083

Bailey, S. (2011). Academic writing: A Handbook for International Students (3 ${ }^{\text {rd }}$ ed.). London: Routledge.

Chittum, J. R., \& Bryant, L. H. (2014). Reviewing to learn: Graduate student participation in the professional peer-review process to improve academic writing skills. International Journal of Teaching and Learning in Higher Education, 26(3), 473-484. Retrieved from http:/ /www.isetl.org/ijtlhe/pdf/IJTLHE1984.pdf

Crème, P., \& Lea, M. R. (2000). Writing at university: A guide for students. Buckingham: Open University Press.

Doyle, T. (2008). Helping students learn in a student-centered environment. Sterling, VA: Stylus.

Evans, S., \& Morrison, B. (2011). The first term at university: implications for EAP. ELT Journal, 65(4), 387-397. https://doi.org/10.1093/elt/ccq072

Ezza, E-S. Y., \& Al-Jaralla, N. (2015). EAP as an index of academic excellence in medical studies at Majma'ah University. In A. K. Hamdan (Ed.), Teaching and learning in Saudi Arabia: Perspectives from higher education (pp. 175-184). Rotterdam: Sense Publishers.

Fadel, S., \& Rajab, H. (2017). Investigating the English language needs of the female students at the faculty of computing and information technology at King Abdulaziz University in Saudi Arabia. English Language Teaching, 10(6), 69-82. http://doi.org/10.5539/elt.v10n6p69

Fischer, B. A., \& Zigmond, M. J. (1998). Survival skills for graduate school and beyond. New Directions for Higher Education, 101, 29-40. http:/ / dx.doi.org/10.1002/he.10103

Goalty, A. (2000). Critical reading and writing: An introductory coursebook. London: Routledge.

Grabe, W., \& Kaplan, R. B. (2014). Theory and practice of writing: An applied linguistic perspective. New York, NY: Routledge.

Hamdan, A. K. (Ed.). (2015). Teaching and learning in Saudi Arabia: Perspectives from higher education. Rotterdam: Sense Publishers.

Hartley, J. (2008). Academic writing and publishing: A practical guide. New York: Routledge.

Hogue, A., \& Oshima, A. (2006). Introduction to academic writing. Essex: Pearson.

Huwari, I. F., \& Al-Khasawneh, F. M. (2013). The Reasons behind the Weaknesses of Writing in English among Prep-Year Students at Taibah University, School of Education, Communication and Language Sciences. English for Specific Purposes World, 38(14), 1-9. 
Joseph, A. (1998). Put it in writing: Learn how to write clearly, quickly, and persuasively. New York: McGraw-Hill.

Kamler, B. (2008). Rethinking doctoral publication practices: Writing from and beyond the thesis. Studies in Higher Education, 33(3), 283-294. https://doi.org/10.1080/03075070802049236

Khan, I. A. (2011). Learning difficulties in English: Diagnosis and pedagogy in Saudi Arabia. Educational Research, 2(7), 1248-1257. Retrieved from https://www.interesjournals.org/articles/learning-difficulties-in-englishdiagnosis-and-pedagogy-in-saudi-arabia.pdf

Kvale, S., \& Brinkmann, S. (2009). Interviews: Learning the craft of qualitative research interviewing ( $2^{\text {nd }}$ ed.). Thousand Oaks, CA: Sage.

Paltridge, B., \& Starfield, S. (Eds.). (2013). The handbook of English for specific purposes. Malden, MA: Wiley-Blackwell. https://doi.org/10.1002/9781118339855

Pfeifer, H. L., \& Ferree, C. W. (2006). Tired of "reeding" bad papers? Teaching research and writing skills to criminal justice students. Journal of Criminal Justice Education, 17(1), 121-142. https:// doi.org/10.1080/10511250500335692

Rose, M., \& McClafferty, K. A. (2001). A call for the teaching of writing in graduate education. Educational Researcher, 30(2), 27-33. https:// doi.org/10.3102/0013189X030002027

Shukri, N. A. (2014). Second language writing and culture: Issues and challenges from the Saudi learners' perspective. Arab World English Journal 5(3), 190-207.

Singleton-Jackson, J., Lumsden, D. B., \& Newsom, R. (2009). Johnny still can't write, even if he goes to college: A study of writing proficiency in higher education graduate students. Current Issues in Education, 12. Retrieved from http://cie.asu.edu/ojs/index.php/cieatasu/article/vie w/45/9

Surratt, C. K. (2006). Creation of graduate oral/written communications skills course. American Journal of Pharmaceutical Education, 70(1), 5. https://doi.org/10.5688/aj700105

USC Libraries, Research Guides. (2020). Academic Writing: Definition. Retrieved from https://libguides.usc.edu/writingguide/academicwriting

\footnotetext{
i The research guidelines at the website read as follows: "Academic writing refers to a style of expression that researchers use to define the intellectual boundaries of their disciplines and their specific areas of expertise. Characteristics of academic writing include a formal tone, use of the third-person rather than first-person perspective (usually), a clear focus on the research problem under investigation, and precise word choice. Like specialist languages adopted in other professions, such as, law or medicine, academic writing is designed to convey agreed meaning about complex ideas or concepts for a group of scholarly experts."
} 


\section{Appendix A: Assignment}

Name:

Participant No.:

Department/Faculty:

Marks Obtained:

\section{Note: Read the following observation carefully.}

Many Saudi students going to foreign countries for higher studies, like the US, the UK, New Zealand, and so on, face problems and difficulties in their education because they are not well-prepared to receive education in English medium. The reason for this lies in their lack of proper training in academic writing. Most of them are very good at their chosen fields of study such as, natural sciences, mathematics, engineering, medicine or law, but they achieve low marks because of major drawbacks in academic writing. More specifically, their writing skills are found to be unsatisfactory, especially in writing for research, owing to which they fail to write excellent academic essays and publishable research articles. It is suggested that universities in Saudi Arabia should offer English for Academic Purposes (EAP) program to all undergraduate students to train the students in the skills of academic writing, not only for studies in foreign countries but also for universities at home.

Based on the information provided in the passage above, prepare the outline of a research essay in accordance with the sections given below:

The research problem

Research hypothesis and research question(s)

Research Hypothesis

\section{Research Question(s)}


Research methodology

Aims and objectives of the research

Titles of five research articles related to the topic

1.

2.

3.

4.

5.

Significance of the research (for the university) 
Summary of three articles chosen as sources

1.

2.

3.

Introduction, including your main argument for research

Sample in-text citation of the selected sources in the chosen style (APA/MLA/Chicago)

List of References

1.

2. 
3.

4.

5.

\section{Appendix B: Interview format}

\section{Structured Interview}

Dear Research Participant,

Please write answers to the following questions in the space provided, according to your understanding. Your answers will be assessed for your knowledge of the topics, therefore, please do not consult any online or offline materials to answer the questions. Thank you.

1. What are the essential components of a well-researched, publishable essay?

Components of research essay: Introduction, Method,

2. What are different research methods? Briefly explain one of the research methods.

3. How are research essays contextualized in their area of research? 
4. What is research hypothesis, and how is it related to research questions?

5. What are the different sources of collecting materials in support of the main argument in a research essay? Write as many sources as possible.

6. What do you understand by 'citing the sources' in a research essay?

7. What is in-text citation?

8. What do you understand by 'formatting' of an essay? 
9. Write the names of three prevalent citation and formatting styles.

10. What information is to be provided in the References/ Bibliography section of a research essay?

11. What is the purpose of 'Notes' section in a research essay?

How do you feel about writing a research essay? Do you find the task easy or difficult? 